Abstracta Iranica Abstracta Iranica

Revue bibliographique pour le domaine irano-aryen

Volume 42-43 | 2021

Comptes rendus des publications de 2019-2020

\title{
Paolo Raffaele Pugliese. L'infinito giardino interiore: la mistica di Giovanni di Dalyatha e di Gregorio di Nissa
}

\section{Florence Jullien}

\section{(2) OpenEdition}

Journals

\section{Édition électronique}

URL : https://journals.openedition.org/abstractairanica/54246

DOI : 10.4000/abstractairanica.54246

ISSN : 1961-960X

Éditeur :

CNRS (UMR 7528 Mondes iraniens et indiens), Éditions de l'IFRI

Référence électronique

Florence Jullien, « Paolo Raffaele Pugliese. L'infinito giardino interiore: la mistica di Giovanni di Dalyatha e di Gregorio di Nissa », Abstracta Iranica [En ligne], Volume 42-43 | 2021, document 39, mis en ligne le 30 décembre 2021, consulté le 13 décembre 2022. URL : http://journals.openedition.org/ abstractairanica/54246 ; DOI : https://doi.org/10.4000/abstractairanica.54246

Ce document a été généré automatiquement le 13 décembre 2022.

Tous droits réservés 


\title{
Paolo Raffaele Pugliese. L'infinito giardino interiore: la mistica di
} Giovanni di Dalyatha e di Gregorio di Nissa

\author{
Florence Jullien
}

\section{RÉFÉRENCE}

Paolo Raffaele Pugliese

Paolo Raffaele Pugliese. L'infinito giardino interiore: la mistica di Giovanni di Dalyatha e di Gregorio di Nissa. Rome: Pontificio Istituto Orientale/Valore Italiano, 2020, 208 p. ISBN : 9788897789819.

1 Cet ouvrage fera découvrir auprès d'un large public italien la mystique de Jean de Dalyatha, moine syriaque qui vécut au Moyen-Orient au VIII siècle et que les travaux pionniers de Robert Beulay ont fait connaître, et les écrits du Père cappadocien Grégoire de Nysse. L'A. effectue une comparaison de leurs expériences spirituelles et mystiques, et de leurs mises en narration.

\section{AUTEUR}

FLORENCE JULLIEN

CNRS, CeRMI, Paris 